\title{
EGU21-3265
}

https://doi.org/10.5194/egusphere-egu21-3265

EGU General Assembly 2021

(c) Author(s) 2021. This work is distributed under

the Creative Commons Attribution 4.0 License.

\section{An integrated geophysical-petrological view of the lithosphere of the northern Apennines, Dinarides and Pannonian Basin.}

\author{
Montserrat Torne ${ }^{1}$, Wentao Zhang ${ }^{1,2}$, Ivone Jimenez-Munt ${ }^{1}$, Ana Negredo ${ }^{3,4}$, Estefania Bravo ${ }^{1,2}$ \\ Jaume Vergés ${ }^{1}$, and Daniel García-Castellanos ${ }^{1}$ \\ ${ }^{1}$ Geosciences Barcelona (Geo3Bcn $1 \mathrm{CSIC}$ ), Barcelona, Spain (mtorne@geo3bcn.csic.es) \\ ${ }^{2}$ Department of Earth and Ocean Dynamics, University of Barcelona, Barcelona, Spain \\ ${ }^{3}$ Department of Physics of the Earth and Astrophysics, Complutense University of Madrid, Madrid, Spain \\ ${ }^{4}$ Institute of Geosciences IGEO, UCMICSIC, Madrid, Spain
}

The present-day structure of the lithosphere and uppermost mantle of Northern Apennines and Dinarides region results from a complex tectonic scenario mainly driven by subduction of Tethyan oceanic domains. The study area and surrounding regions have been the goal of a large number of geophysical studies that have provided information on the velocity, density and temperature distribution in the lithosphere and uppermost mantle. However, the majority of them do not consider the contribution of the chemical composition and phase transitions on the physical properties in the lithospheric mantle. By applying and integrated petrological-geophysical approach -LitMod2D_2.0- we aim at constraining and characterizing the present-day lithosphere and mantle structure along a NE-SW trending $730 \mathrm{~km}$ long geo-transect crossing the Northern Tyrrhenian Sea, the Northern Apennines, the Adriatic Sea, the Dinarides fold belt and the Pannonian back-arc basin. Along the modelled geotransect, we infer the spatial distribution of density, thermal conductivity and seismic velocities based on the variations of gravity, geoid, elevation and heat flow consistently with the thermochemical conditions and with isostatic equilibrium. Our results show significant lateral variations in the lithospheric structure, affecting crustal and lithospheric mantle thickness, temperature, density distribution, and mantle composition that reveals the imprint of the complex geodynamic evolution of the area. This is a GeoCAM contribution (PGC2018-095154-B-I00)

Keywords: Alpine Mediterranean orogeny, geoid and gravity anomalies, elevation, integrated petrological-geophysical modelling, mantle seismic P and S-wave velocity. 